\title{
Resources Requirement and Routing in Courier Service ${ }^{1}$
}

\author{
C.K.Y. Lin \\ Department of Management Sciences, City University of Hong Kong \\ Hong Kong, P.R.O.C.
}

\section{Introduction}

Providing cost-effective and efficient services are important to both courier companies and their contract customers. This work proposes modelling of multi-resource domestic courier operations with the aim of improving the service in terms of meeting a specific time window for pickup/delivery at minimum total cost. The characteristics of this pickup and delivery operations are (a) one delivery resource (e.g., van) can transport both customer items and a non-identical, lighter resource (e.g., courier); (b) item transfer is allowed between resource units where the transfer location(s) is to be decided, say among customer sites. In actual practice of some courier companies, the driver of a van can service customers like couriers. In other occasions, the van is used to transport couriers or return the collected documents in busy districts. Resources estimation and computerized scheduling methods will facilitate contract preparation with customers. Scheduling results can enable regular performance monitoring of daily operations.

This work is motivated by a local courier service of a multi-national logistics company operating with multiple delivery resources (vans, scooters and couriers on foot). Two nonidentical resources (vans and couriers) and their two types of cooperation described in (a) and (b) above are modelled and a solution method presented. (In a similar modelling approach, the third resource could also be incorporated, but will not be included here.) In each service session, a given set of $N$ customers is to be served. Each customer is associated with two time window requirements: one for document pickup at the customer site and another for delivery to the mail centre to meet the designated flight departure time. The current problem belongs to the class of static-deterministic pickup and delivery problem with time windows (PDPTW) where there are many pickup points and only a single, common delivery point at the mail centre (referred to as depot here). Pickups occur before delivery to the mail centre. Express documents are usually letters/small parcels, which are not constrained by the transportation capacity of carriers. The objective is to find the minimum cost solution for the two resources to servicing all customers and satisfying the time window constraints in this special case of PDPTW - the many pickup-to-one delivery problem with time window constraints and without capacity constraints. The output includes the number of units required by resource and their routes servicing the customers.

1 The work described in this paper was fully supported by the Strategic Research Grant from City University of Hong Kong (Project No. 7002261)

Source: Vehicle Routing Problem, Book edited by: Tonci Caric and Hrvoje Gold, ISBN 978-953-7619-09-1, pp. 142, September 2008, I-Tech, Vienna, Austria 
Pickup and delivery problems (PDPs) with cooperative operations and transfer opportunity have small coverage in literature, not to mention time windows and multiple non-identical delivery resources. The contribution of this work includes modelling and presenting an exact method for solving a PDPTW with two non-identical resources and cooperative operations described in (a) and (b) above. Comparison with the independent operations will be made on instances generated from real data and simulated data. This work will serve as foundation for developing other exact and heuristic methods in the static or dynamic problem.

\section{Literature review}

There is a vast amount of literature on pickup and delivery problems and several surveys (e.g., Savelsbergh \& Sol, 1995; Ropke \& Pisinger, 2006). There is relatively few PDPs on cooperative operations or with transfer opportunity. One of them is a multi-criteria PDP (Shang \& Cuff, 1996), allowing transfer of hospital documents between vehicles provided no additional travel time is incurred. A look-ahead heuristic was developed for the dynamic situation as it was reported that there were no exact algorithms to solve similarly sized problems. Transfer operations occurred in express mail services in which vehicles could operate as a feeder-backbone system or/and "am-pm" hub system (Kamoun \& Hall, 1996) for large metropolitan area. Each feeder vehicle (small van) assigned to serve a district/route would visit a drop-box periodically to put in the collected documents. A backbone vehicle would move the outbound mail from the drop-box to the sorting facility. In return, the backbone vehicle would collect the inbound mail to be placed in the appropriate drop-box. From there, the feeder starts to deliver the document to its destination. Location of drop-boxes are static and may not be optimal for a given set of demand data. The adoption of transshipment points (like drop-boxes) and the benefit (reduction of total travel distances) were examined in a PDPTW solved by applying a construction and improvement heuristic (Mitrovic-Minic \& Laporte, 2006). The locations of transshipment point are tested systematically at several static, convenient locations.

An example of cooperative operations in vehicle routing problems is the truck and trailer routing problem (TTRP), where customers are served by one (or more) of the following three routes: (i) a pure truck route, (ii) a complete vehicle route containing a truck and a trailer as one unit or (iii) a complete vehicle route where the trailer is parked somewhere such that the truck can visit customer locations that are less easily accessible by a complete vehicle. This problem can be formulated as an integer programming model and solved heuristically by a two-phase procedure (Semet, 1995). The first phase assigns trailers to trucks and determines customers to be served by each truck or complete vehicle (truck plus trailer), followed by the second phase of routes generation. Other heuristics for this problem include construction and improvement heuristics (Gerdessen, 1996) ; construction heuristics further improved by specially designed tabu search (Chao, 2002; Scheuerer, 2006) and simulated annealing ( $\mathrm{Yu}$ et al., 2008). Simplifying assumptions in modelling this complex problem were made, like assuming each trailer is parked exactly once (Gerdessen, 1996); or each customer site can be a candidate parking place (Gerdessen, 1996; Chao, 2002). The assumption of making each customer site a candidate location for documents transfer is also adopted in the present study. The differences are that pickup and delivery time windows are considered here; vehicle capacity constraint can be ignored for express documents. Furthermore, the frequency of cooperation among non-identical delivery resources (for 
documents transfer or returning to depot together) is unrestricted, but decided by a model. This work is an extension of solving an uncapacitated PDPTW allowing transfer of documents between units of a single vehicle type (Lin, 2008). Computational results indicate savings in total cost and vehicles over a construction heuristic for a capacitated PDPTW (Lu and Dessouky, 2006) as problem size grows. Besides, such a cooperative strategy (allowing document transfer) with multiple use of vehicles achieve cost savings over the independent strategy. In this work, two operational modes, one independent and one cooperative, of the two resources are analyzed to examine the objective (total cost) value and computational time involved: independent operations; cooperative operations allowing document transfer and return transport (of lighter resource unit(s) by the heavier resource).

The remaining of this chapter is organized as follows. Section 3 describes the model assumptions based on some current practice. Formulation of the independent operations and cooperative operations are given in Section 4 and 5, respectively. Computational experiments based on instances generated from real data and simulated data are presented in Section 6. The last section summarizes the contribution of this work and points to future research areas.

\section{Model assumptions}

After understanding the practice of a courier service, major operating parameters are collected and model assumptions are made. The majority of customer requests occur on Mondays to Fridays. A day's work is typically divided into two half-day service sessions: morning and afternoon. Customer pickup and delivery time windows are placed in the same session. Hence, each session represents an independent problem. Problem size reduction can also be achieved through clustering locations into independent sub-problems. In their planning, vehicle capacity constraint (on carrying express documents) can be ignored. This assumption was also adopted for the pickup and delivery operations of parcels or medical records (Langevin \& Soumis, 1989; Mitrović-Minić et al., 2004; MitrovićMinić \& Laporte, 2004; Shang \& Cuff, 1996). Here, a capacity constraint is associated with the heavier resource in carrying the lighter resource unit(s).

For a set of $N$ customers given in a service session, the pickup time window for customer $i$ $(i=1, \ldots, N)$ with pickup time specified at $t_{i}$ is $\left[t_{i}-\delta_{P}, t_{i}\right]$, where a given early allowance $\delta_{P}(>$ 0 ) is common to all customers and same for each resource. An amount of on-site service time $\varphi$ is expected at each customer site. The delivery location for all customers is the mail centre at which parcels are processed before outbound delivery. For customer $i$, the time window for delivery time specified at $\tau_{i}$ is $\left[0, \tau_{i}+\delta_{D}\right]$, where a given lateness allowance $\delta_{D}(>0)$ is common to all customers. The assumptions in this work extend from those in an earlier work (Lin, 2008) for a single resource. Additional assumptions characterize the cooperative mode between the two resources. The heavier resource, once assigned a customer group (or route), is assumed to be dominant and the lighter resource will subordinate to its operations. The route and scheduled times of the heavier resource is not delayed by carrying units of the lighter resource. All assumptions are listed as follows:

i. The service session is of duration $T$.

ii. Each unit of the heavier resource (labelled as resource 2) consists of an operator (also a unit of the lighter resource, labelled as resource 1) and a vehicle. Like resource 1, this composite unit can service customers, transport other units of resource 1 or its collected documents. 
iii. The capacity of each resource is not constrained in carrying customer documents.

iv. Resource 2 is constrained in carrying resource 1 units. Each unit of resource 2 can carry $C$ units of resource 1 , including the operator of resource 2 .

v. The pickup request at each customer location occurs before the delivery request to the common delivery location (depot or mail centre). Both must be serviced by the same resource unit, unless an item is transferred to another resource after pickup. (It is naturally possible to transfer documents between different units of the same resource. This has been modelled in an earlier work (Lin, 2008) and will not be considered here.)

vi. Travel time between a pair of locations (different between the two resources) could be asymmetrical or symmetrical.

vii. The travelling speed of resource $k(k=1,2)$ is assumed to be an average of $V_{k} \mathrm{~km} /$ hour. (The data on travelling speed will be used to convert the travel distance, collected or simulated, into estimated travel time.)

viii. The unit travelling costs of the two resources are assumed to be proportional to their travelling speed.

ix. Pickup at the customer site should be no earlier than $\delta_{P}$ minutes before the specified pickup time.

x. Waiting is allowed if a resource unit arrives before the earliest pickup time at the customer site.

xi. On-site service time is assumed to be $\varphi$ minutes.

xii. Delivery time at the delivery location (depot or mail centre) should be no later than $\delta_{D}$ minutes after the specified delivery time.

xiii. Each unit of a resource can start out and return to the depot one or more times during the service sesssion.

xiv. When a unit resource starts out a second time from the depot, it can only visit a group of customer(s) whose latest pickup times and delivery times at the depot can be satisfied. (This applies to subsequent routes whenever the unit starts out from the depot.)

$\mathrm{xv}$. When a unit resource 2 has collected its assigned customer documents, the customer location prior to returning to depot is a candidate site for documents transfer or picking up units of resource 1 . Some (or all) resource 1 units may return together with resource 2; others may simply transfer its collected documents and continue to service other customers. Apart from these opportunities, no transportation of resource 1 units is considered to reduce risk of waiting and delay.

xvi. Transfer of collected documents or return together with resource 2 (in $(x v))$ is considered by checking two constraints: arrival time of a unit resource 1 at the transfer location (say customer $i$ ) is on or before the earliest pickup time (i.e., $t_{i}-\delta_{P}$ ); the latest departure time at this transfer location (i.e., $t_{i}+\varphi$ ) still satisfies the delivery time window constraints at the depot (mail centre) for the collected documents.

xvii. The objective function of monthly total cost comprises the fixed cost and travelling cost of resource units, assuming a 5-day workweek and 4 weeks per month.

\section{Modelling independent operations}

It is common in vehicle routing and PDP literature to assume indepedent vehicle operations. The advantage of independence is the flexibility offered to vehicles to react to real-time changes without affecting other vehicles. Besides, the modelling approach and solution 
methods are simpler than a cooperative strategy even for identical vehicles (Lin, 2008). An objective of this work is to examine possible cost savings and computational time required as delivery resources operate in some cooperative modes. Hence, the results from independent operations of the two resources can serve as a basis for comparison (Section 6). Firstly, all independent customer groups that can be visited by each unit of a resource in a single route (starting and ending at depot) are found by enumerating all possible customer sequences in an enumeration tree (Bronmo et al., 2007). Let $n_{k}$ be the number of feasible customer groups formed for resource $k(k=1,2)$. A resource unit could be assigned multiple routes in a service session (assumption (xiii)) as it has to return documents to the depot to fulfil the delivery time window constraints, possibly before the session ends. The multiroute operations are represented by connected nodes in a network. Customer groups (sequence of customers visited in a single route) form nodes of this network, denoted by $\Pi=$ $(\Psi, A)$, where $\Psi$ and $A$ represent the node set and arc set, respectively.

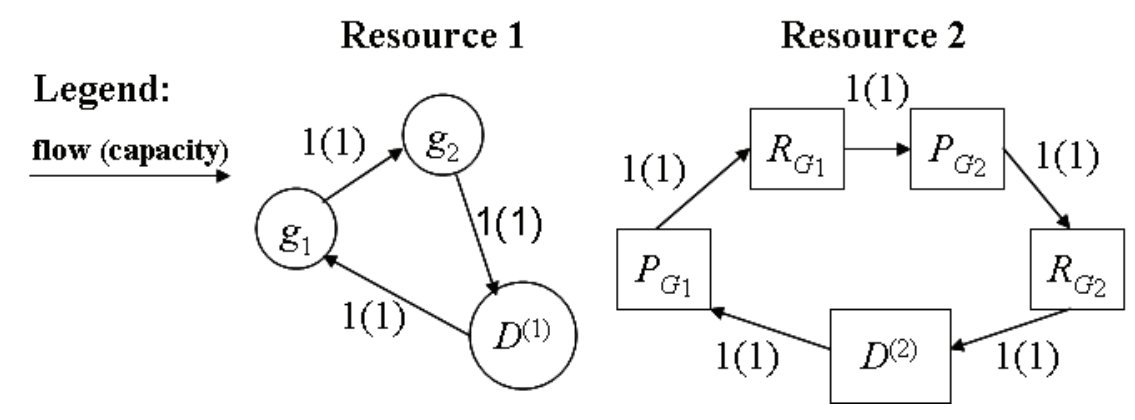

Fig. 1. Independent operations of two resource units

Figure 1 depicts instances of independent operations of a unit of each resource represented in $\Pi$. A unit resource 1 starts out from the depot (node $\left.D^{(1)}\right)$ to pick up group $g_{1}$ documents and returns to the depot (not shown in figure). Then it starts out again to pick up group $g_{2}$ documents and return to the depot (node $D^{(1)}$ ) to end its service. Similarly, a unit resource 2 first leaves the depot (node $D^{(2)}$ ) for group $G_{1}$ documents. On returning them to the depot (node $R_{G 1}$ ), it starts out again to pick up group $G_{2}$ documents and return to the depot (node $\left.D^{(2)}\right)$ to end its service. Details of constructing network $\Pi$ are explained as follows.

Node set $\Psi$ : The single depot is represented by nodes $D^{(1)}$ and $D^{(2)}$ for resource 1 and 2, respectively. Each independent customer group, say $g_{i}$, of resource 1 forms a node itself $(i=$ $\left.1, \ldots, n_{1}\right)$. Each independent customer group, say $G_{i}$, of resource 2 generates two nodes, $P_{G i}$ and $R_{G i}\left(i=1, \ldots, n_{2}\right)$. Node $P_{G i}$ represents selection of customer group $G_{i}$ to be serviced by a unit resource 2. Node $R_{G i}$ is a copy of the depot, to where resource 2 can return the collected documents of group $G_{i}$ and start out again, if necessary. (The reason for adopting two nodes for each customer group of resource 2 is to allow future addition of cooperative arcs to be introduced in the subsequent sections. Hence, $\Pi$ will be expanded systematically, aiming to obtain better solutions by cooperation between resource units.)

Arc set $A$ : Each arc defined has the time constraints checked between its start node and end node. Each resource is associated with arcs defined on its own customer groups. Arc capacity is one unit for all arcs as there is no interaction between the two resources under independent operations. Seven types of arcs are defined in $\Pi$ : 
- $\quad\left(D^{(1)}, g\right)$ : Group $g$ is selected. A unit resource 1 starts out from the depot (node $\left.D^{(1)}\right)$ to collect documents in group $g$. (Arc cost is the sum of fixed cost of a unit resource 1 and the travelling cost servicing group $g$.)

- $\quad\left(g_{i}, g_{j}\right)$ : Group $g_{i}$ documents have been collected and returned to the depot by a unit resource 1. It starts out again from the depot to collect documents in group $g_{j}(i \neq j)$. (The feasibility check for defining this arc ensures that even if the unit returns to the depot at the latest time of group $g_{i}$ documents, it will not violate the pickup and delivery time windows of group $g_{j}$. This arc models multi-route assignment to each unit resource 1 within a service session. Arc cost is the travelling cost servicing group $g_{j}$ from and back to the depot.)

- $\quad\left(g, D^{(1)}\right)$ : Group $g$ documents are returned to the depot and the unit resource 1 ends its service at node $D^{(1)}$ (depot). (Arc cost is 0 .)

- $\quad\left(D^{(2)}, P_{G}\right)$ : Group $G$ is selected. A unit resource 2 starts out from the depot (node $\left.D^{(2)}\right)$ to collect documents in group $G$. (Arc cost is the fixed cost of a unit resource 2.)

- $\quad\left(P_{G}, R_{G}\right)$ : Group $G$ documents have been collected by a unit resource 2 which will return directly to the depot (node $R_{G}$ ) from the last customer location in $G$. (Arc cost is defined as the travelling cost servicing group $\mathrm{G}$, from and back to the depot.)

- $\quad\left(R_{G i}, P_{G j}\right)$ : Group $G_{i}$ documents have been delivered to the depot (meeting the earliest delivery time constraint of Group $G_{i}$ documents). A unit resource 2 start outs again to collect documents in group $G_{j}\left(\neq G_{i}\right)$. The start time from the depot is determined by the earliest return time of Group $G_{i}$ documents. (This arc models multi-route assignment to each unit resource 2 within a service session. Arc cost is 0 .)

- $\quad\left(R_{G}, D^{(2)}\right)$ : Group $G$ documents are returned to the depot and the unit resource 2 ends its service at node $D^{(2)}$ (depot). (Arc cost is 0 .)

Naturally, there is more than one way to model (independent) multi-route operations. An exact method includes enumerating all possible sequences of single routes, one after another, to form feasible sets of multi-route solutions for selection. However, this approach makes it difficult to model interaction and cooperation between different routes. The proposed network $\Pi$ is a simpler representation. Nevertheless, some multi-route solutions have not been included due to assumption (xiv) made to simplify modelling. With the independent solutions represented by $\Pi$, the optimal solution can be obtained from an integer programming model:

Model P: Integer programming model for independent operations of two resources Basic parameters

$S_{k j}=$ set of customer groups of resource $k(=1,2)$ that can service customer $j(j=1, \ldots, N)$

$W_{k}=$ fixed cost per unit resource $k(=1,2)$.

$\chi_{g}^{(1)}=$ travelling cost of a unit resource 1 in servicing customer group $g$, including the trips out of and return to the depot, $g=1, \ldots, n_{1}$

$\chi_{G}^{(2)}=$ travelling cost of a unit resource 2 in servicing customer group $G$, including the trips out of and return to the depot, $G=1, \ldots, n_{2}$

\section{Decisions:}

$y_{i j}=$ flow (or connection) along arc $(i, j), \forall(i, j) \in A$

$$
\text { Min. } Z=\sum_{g=1}^{n_{1}} W_{1} \cdot y_{D^{(1)}, g}+\sum_{G=1}^{n_{2}} W_{2} \cdot y_{D^{(2)}, P_{G}}+\sum_{g=1}^{n_{1}} \sum_{(i, g) \in A} \chi_{g}^{(1)} \cdot y_{i, g}+\sum_{G=1}^{n_{2}} \chi_{G}^{(2)} \cdot y_{P_{G} R_{G}}
$$


subject to:

$$
\begin{gathered}
\sum_{g \in S_{1 j}} \sum_{(i, g) \in A} y_{i, g}+\sum_{G \in S_{2 j}} \sum_{\left(i, P_{G}\right) \in A} y_{i, P_{G}}=1, j=1, \ldots, N \\
\sum_{(k, i) \in A} y_{k, i}=\sum_{(i, j) \in A} y_{i, j}, \forall i \in \Psi \\
y_{i j}=0,1, \forall(i, j) \in A
\end{gathered}
$$

The objective function in constraint (1) is the (monthly) total cost, comprising the fixed costs of resources and travelling cost of servicing customer groups. Each customer must be visited exactly once in one of the customer groups. This is formulated in constraint (2). Constraint (3) describes the flow balance equation for each node in the network, with flow variables defined as binary integers in constraint (4). (In many instances, the integer variables of $y_{i j}$ can be relaxed and the resulting optimal solution still maintains the integer property.)

\section{Modelling transfer operations and return transporation}

This section models the cooperative operations between units of the two resources by allowing documents transfer and/or return transportation of resource 1 units by resource 2 . Such cooperation is represented by additional arcs embedded into network $\Pi$. There are certain rules defining the transfer operations and return transportation in this model, respectively. A unit resource 1 on collecting all documents in its assigned customer group can travel to transfer the collected documents to a unit resource 2 returning to the depot (from its last customer location), provided that it does not incur delay to the resource 2 unit and the delivery time constraints for both customer groups can be satisfied (assumption $(\mathrm{xv}))$. After transfer, the resource 1 unit is free to service other customer groups from the transfer location. (Note that resource 2 stays dominant and its schedule would not be affected by document transfer or transporting others.) Alternatively, the resource 1 unit can return to the depot together with the resource 2 unit to save travelling cost. On its return to the depot, the resource 1 unit ends it service. To model the cooperations in this section, network $\Pi$ (for modelling the independent operations)will be expanded by including additional nodes and arcs. The expanded network is denoted by $\Pi^{T}\left(\Psi^{T}, A^{T}\right)$, where $\Psi^{T}$ and $A^{T}$ represent the node set and arc set, respectively. Figure 2 depicts two types of cooperations between two resource units, to be represented in the network $\Pi^{T}$. In Figure 2(i), a unit resource 1 starts out from the depot (node $D^{(1)}$ ) to pick up documents of a customer group, denoted by $g^{\mathrm{T}}$. This unit then travels to a transfer node $\mathrm{T}_{1}$ which is the customer location of a resource 2 group $G_{1}$ prior to returning to depot. After documents transfer, the unit resource 1 continues to service another group $\mathrm{g}_{2}$ before ending its service at the depot (node $D^{(1)}$ ), while the unit resource 2 returns with the collected and transferred documents $\left(G_{1}\right.$ and $\left.g^{\mathrm{T}}\right)$ to the depot (node $D^{(2)}$ ) and ends it service. Figure 2(ii) depicts the case of return transportation of a unit resource 1 by resource 2 . A unit resource 1 starts out to collect group $g$ documents, returns them to the depot and continues to service group $g^{T}$. After picking up group $g^{T}$ documents, it joins a unit resource 2 at the last customer location of its assigned group $G_{2}$. Both return together to their respective depot (possibly the same physical location) and end their service. 


\section{Legend:}

flow (capacity)

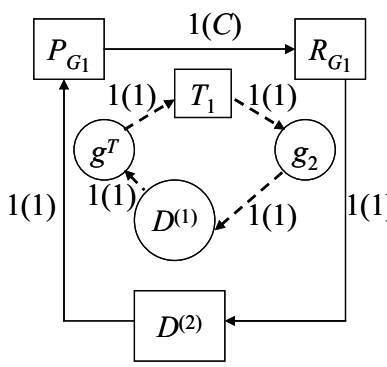

(i)

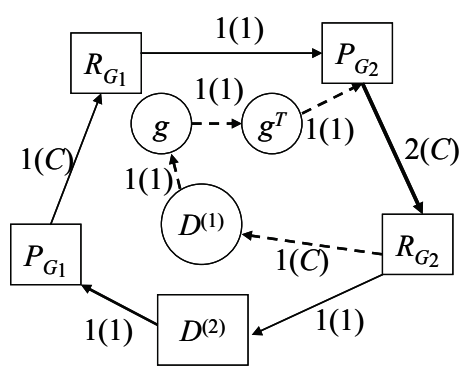

(ii)

Fig. 2. Modelling cooperative operations between two resource units: (i) documents transfer and (ii) return transportation

Node set $\Psi^{T}$ : In addition to nodes defined in $\Psi$, two types of new nodes will be included. The first type defines resource 1 transfer groups which represents the sequences of customers that can be visited by a unit resource 1 in a single route, starting from the depot and ending at a transfer node. The transfer node is selected at a customer site based on assumption (xvi). (The customer at this site is the last customer in a route for a resource 2 unit.) Transfer groups are found by enumerating all possible customer sequences as for the independent customer groups. As the return time by resource 2 (from the transfer node) is faster, more customers can be visited by a unit resource 1 in a single route before heading for transfer. Hence, there are more transfer groups than pure customer groups for resource 1. Let $n_{1}^{T}$ be the number of transfer groups formed for resource 1. Each transfer group, say $g_{i}^{T}$, of resource 1 forms a node itself $\left(i=1, \ldots, n_{1}^{T}\right)$ in network $\Pi^{T}$. The second type of new nodes is the set of transfer nodes. A total of $N$ transfer nodes, $T_{1}, T_{2}, \ldots, T_{N}$, are formed, representing customer location 1,2, ., $N$ respectively. (As a customer could belong to more than one customer group, each transfer node can be associated with one or more customer groups of resource 2 to be connected by arcs in network $\Pi \Pi^{T}$.)

Arc set $A^{T}$ : In addition to arcs in $A$, new arcs are defined to model the cooperative operations in this section. Each new arc is checked for feasibility of time constraints between its start node and end node. Changes in paramters associated with arcs in $A$ will be described.

- $\quad\left(D^{(1)}, g^{T}\right)$ : Transfer group $g^{T}$ is selected. A unit resource 1 starts out from the depot (node $D^{(1)}$ ) to collect documents in this group and travels to the last site for documents transfer to some resource 2 unit. (Arc capacity is one and arc cost is the sum of fixed cost of a unit resource 1 and the travelling cost servicing group $g^{T}$.)

- $\quad\left(g^{T}, P_{G}\right)$ : This arc models return transportation. A unit resource 1 , on collecting customer documents in transfer group $g^{T}$, joins a unit resource 2 at the last customer location (also a candidate transfer node) of its assigned group G. They return together to the depot in the same vehicle. (Arc capacity is one and arc cost is 0 .)

- $\quad\left(P_{G}, R_{G}\right)$ : Same interpretation as in arc set $A$, but arc capacity is changed to $C$ (i.e., carrying capacity of resource 1 units, including the operator, by a unit resource 2 ). 
- $\quad\left(R_{G}, D^{(1)}\right)$ : This arc models return transportation. This new arc allows resource 1 unit(s) to be carried by a unit resource 2, responsible for Group $G$ documents, to return to node $D^{(1)}$ (depot) and ends its service. (Arc capacity is $C$ and arc cost is 0 .)

- $\quad\left(g^{T}, T_{i}\right)$ : This arc models pure document transfer. A unit resource 1 , on collecting customer documents in transfer group $g^{T}$, transfers its documents to a unit resource 2 servicing customer $i$ (transfer location), before its return to depot. (Note that customer $i$ is stored as the last element in group $g^{T}$ during the enumeration procedure. Arc capacity is one and arc cost is 0 .)

- $\quad\left(T_{i}, g\right)$ : This arc models assignment after document transfer. It allows a unit resource 1 to service customer group $g$ after it is released at customer location $i$, the transfer location. (Arc capacity is one. Arc cost is the travelling cost servicing group $g$ by starting at location $i$ and ending at the depot.)

- $\quad\left(T_{i}, g^{T}\right)$ : Similar interpretation and parameters as for arc type $\left(T_{i}, g\right)$, but the customer group to be serviced is transfer group $g^{T}$ instead.

- $\quad\left(T_{i}, D^{(1)}\right)$ : This arc models the end of service after document transfer. It represents a unit resource 1 returning to node $D^{(1)}$ (depot) to end its service, from the transfer location at customer $i$. (Arc capacity is one and arc cost is the travelling cost from customer $i$ to the depot.)

- $\quad\left(g_{i}, g^{T}\right)$ : Similar to arc type $\left(g_{i}, g_{j}\right)$ in arc set $A$, this arc models the multi-route assignment of a unit resource 1. Group $g_{i}$ documents are returned to the depot and the unit resource 1 starts out again from the depot to collect documents in transfer group $g^{T}$. (Arc capacity is one and arc cost is the travelling cost servicing transfer group $g^{T}$, including the trips from the depot and to the transfer location.)

With the network $\Pi^{T}$ expanded from $\Pi$ to model the cooperative operations, the optimal solution can be obtained from a mixed integer programming model extended from Model $P$ with side constraints:

Model $\Gamma$ : Mixed integer programming model with transfer opportunity and return transportation

Additional parameters

$S^{T}{ }_{1 j}=$ set of transfer groups of resource 1 that can service customer $j(j=1, \ldots, N)$

$L_{2 j}=$ set of customer groups of resource 2 that service customer $j$ last $(j=1, \ldots, N)$

$\chi_{g^{T}}^{(1)}=$ travelling cost of a unit resource 1 in servicing transfer group $g^{T}$, including the outbound trip from depot and the trip to the transfer location, the last element stored in $g^{\mathrm{T}}\left(g^{T}=1, \ldots, n_{1}^{T}\right)$

\section{Decisions:}

$y_{i j}=$ flow (or connection) along arc $(i, j), \forall(i, j) \in A^{T}$

$$
\delta_{P_{G}, R_{G}}=\left\{\begin{array}{ll}
1 & \text { if group } G \text { is serviced by a unit resource } 2, \\
0 & \text { otherwise }
\end{array} \quad G=1, \ldots, n_{2}\right.
$$

$$
\begin{gathered}
\text { Min. } Z=\sum_{g=1}^{n_{1}} W_{1} \cdot y_{D^{(1)}, g}+\sum_{G=1}^{n_{2}} W_{2} \cdot y_{D^{(2)}, P_{G}}+\sum_{g^{T}=1}^{n_{1}^{T}} W_{1} \cdot y_{D^{(1)}, \mathrm{g}^{\mathrm{T}}}+ \\
\sum_{g=1}^{n_{1}} \sum_{(i, g) \in A^{T}} \chi_{g}^{(1)} \cdot y_{i, \mathrm{~g}}+\sum_{G=1}^{n_{2}} \chi_{G}^{(2)} \cdot \delta_{P_{G} R_{G}}+\sum_{g^{T}=1}^{n_{1}^{T}} \sum_{\left(i, g^{T}\right) \in A^{T}} \chi_{g^{T}}^{(1)} \cdot y_{i, \mathrm{~g}^{\mathrm{T}}}
\end{gathered}
$$


subject to:

$$
\begin{gathered}
\sum_{g \in S_{1 j}} \sum_{(i, g) \in A^{T}} y_{i, g}+\sum_{G \in S_{2 j}} \delta_{P_{G}, R_{G}}+\sum_{g^{T} \in S_{1 j}^{T}} \sum_{\left(i, g^{T}\right) \in A^{T}} y_{i, g^{T}}=1, j=1, \ldots, N \\
\sum_{(k, i) \in A^{T}} y_{k, i}=\sum_{(i, j) \in A^{T}} y_{i, j}, \forall i \in \Psi^{T} \\
y_{D^{(2)}, P_{G}}+\sum_{\left(R_{G_{i}}, P_{G}\right) \in A^{T}} y_{R_{G_{i}}, P_{G}}=\delta_{P_{G}, R_{G}}, \forall\left(P_{G}, R_{G}\right) \in A^{T} \\
\sum_{\left(g^{T}, P_{G}\right) \in A^{T}} y_{g^{T}, P_{G}} \leq(C-1) \cdot \delta_{P_{G}, R_{G}}, \forall\left(P_{G}, R_{G}\right) \in A^{T} \\
\sum_{\left(i, T_{j}\right) \in A^{T}} y_{i, T_{j}} \leq(N-1) \cdot \sum_{G \in L_{2 j}} \delta_{P_{G}, R_{G}}, j=1, \ldots, N \\
\delta_{P_{G}, R_{G}}=0,1 ; 0 \leq y_{P_{G}, R_{G}}, y_{R_{G}, D^{(1)}} \leq C \quad \forall\left(P_{G}, R_{G}\right),\left(R_{G}, D^{(1)}\right) \in A^{T} \\
y_{i j}=0,1, \forall(i, j) \in A^{T} \backslash\left\{\left(P_{G}, R_{G}\right),\left(R_{G}, D^{(1)}\right)\right\}
\end{gathered}
$$

The objective function in constraint (5), the demand constraint (6) for each customer and the flow balance constraint (7) for each node in network $\Pi^{T}$ is modified from constraint (1), (2) and (3) in Model P, respectively. (For demand constraint (6), only customer locations in transfer group $g^{T}$ will be considered, but not its last element (transfer location).) Constraints (8) to (10) are the side constraints. Constraint (8) models the relationship between the selection decision $\left(\delta_{P_{G}, R_{G}}\right)$ of a resource 2 customer group $(G)$ and the inflow arcs (of resource 2$)$ to its associated node $\left(P_{\mathrm{G}}\right)$. Constraint (9) formulates the capacity constraint of resource 2 in carrying resource 1 units, before returning to the depot on finishing group $G$. Constraint (10) imposes condition on the use of transfer nodes $\left(T_{\mathrm{j}}\right)$. No document transfer can take place (at customer location $j$ ) if there is no resource 2 units servicing this customer last in its route (i.e., no customer groups in $L_{2 j}$ are selected). The last two constraints (11) and (12) declare the decision variables and their relevant bounds. (In many instances, some binary integer variables can be relaxed without affecting the integer property of the optimal solution.)

\section{Computational experiments}

Computational analysis is carried out based on two types of data. The first set (12 instances) contains customer locations obtained from real-life data of a local delivery service. Each instance contains between 27 to 30 customers. The second set (45 instances) are simulated test problems containing 50, 100 or 150 customers. Data and parameters were obtained from the following sources: 
- From the local delivery service, the pairwise travel distances were provided either by the driver or estimated by geographical information systems (GIS), given the customer and depot locations. The unit travelling cost of resource 2 (vehicle) is $\mathrm{HK} \$ 70$ per hour.

- From a courier service, the duration of a service sesstion $(T)$ is 300 minutes; the on-site service time $(\varphi)$ is 5 minutes; the early allowance $\left(\delta_{P}\right)$ for the pickup time window is 5 minutes; the lateness allowance $\left(\delta_{D}\right)$ for the delivery time window is 10 minutes. The monthly fixed cost per unit resource $1\left(W_{1}\right)$ and resource $2\left(W_{2}\right)$ is $\mathrm{HK} \$ 7,000$ and $\mathrm{HK} \$ 19,000$, respectively. The carrying capacity $(C)$ of resource 1 units by a unit resource 2 is 6.

- The travelling speed of resource $2\left(V_{2}\right)$ is based on the average vehicle travel speed of $20.8 \mathrm{~km}$ /hour from a local study (Transport Department, Hong Kong, 2001).

- $\quad$ The travelling speed of resource $1\left(V_{1}\right)$ is obtained from the average human walking speed of $5 \mathrm{~km}$ /hour from Wikipedia, the free online encyclopedia.

Unknown parameters of pickup times $\left(t_{i}\right)$ and delivery times $\left(\tau_{i}\right)$ for all instances are simulated within the time interval $[0, T]$. For the simulated instances, customer locations are randomly generated in a rectangular travel grid of size $200 \times 200 \mathrm{~min}^{2}$, such that the maximum one-way travel time is around 280 minutes. This is closed to the duration of service session $(T)$ and is reasonable for the size of urban cities. For the simulated instances, the depot locations are systematically set at 3 positions in the travel grid: the edge, the centre and half-way between, to examine the differences in solutions.

The two models (independent Model $P$ and cooperative Model $\Gamma$ ) were coded in Visual Basic.NET 2005 version and all test instances are solved by the optimization software CPLEX 10.1. All experiments were performed on a Pentium 4, $2.5 \mathrm{GHz}$ processor. Comparison between the two models are based on the performance measures of (monthly) total cost, units of each resource required and the computational time taken. Detailed results on cost and resources requirement are recorded in Table 1 and Table 2 for the two types of data respectively. Computational time for all instances are given in Table 3.

An example of optimal solution is shown in Figure 3. A unit resource 2 is assigned two routes: $0 \rightarrow 1 \rightarrow 2 \rightarrow 0 \rightarrow 3 \rightarrow 0$ while a unit resource 1 is assigned a single route to service customer node 4 . After collecting documents at node 4, it travels to node 2 for a free ride back to node 0 (depot) provided by resource 2 .

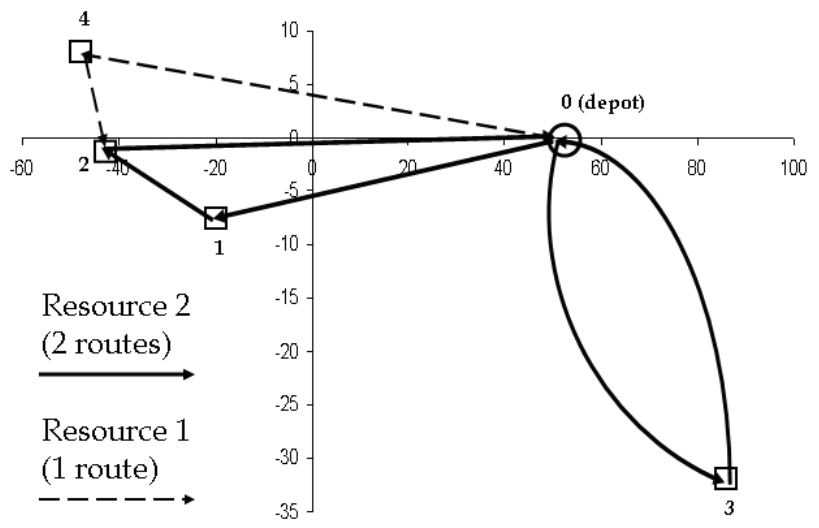

Fig. 3. Optimal cooperation: Return transportation of unit resource 1 by resource 2 (pickup at customer node 2 and jointly return to depot) 


\begin{tabular}{|c|c|c|c|}
\hline \multirow{2}{*}{ Instance } & \multirow{2}{*}{ No. of customers } & \multicolumn{2}{|c|}{$\begin{array}{c}\text { Monthly total cost in } \mathrm{HK} \$ \\
\text { (units required of resource } 2, \text { resource } 1 \\
\text { respectively) }\end{array}$} \\
\hline & & $\begin{array}{c}\text { Independent } \\
\text { operations } \\
(\text { Model } P)\end{array}$ & $\begin{array}{l}\text { Transfer, } \\
\text { return transport } \\
(\text { Model } \Gamma)\end{array}$ \\
\hline 1 & \multirow{4}{*}{27} & $308,320(13,1)$ & $308,320(13,1)$ \\
\hline 2 & & $299,803.33(13,0)$ & $299,803.33(13,0)$ \\
\hline 3 & & $270,740(11,1)$ & $270,740(11,1)$ \\
\hline 4 & & $319,106.67(14,0)$ & $319,106.67(14,0)$ \\
\hline 5 & \multirow{5}{*}{29} & $139,433.33(6,0)$ & $139,433.33(6,0)$ \\
\hline 6 & & $193,836.67(8,0)$ & $193,836.67(8,0)$ \\
\hline 7 & & $337,983.33(14,0)$ & $337,983.33(14,0)$ \\
\hline 8 & & $202,453.33(9,0)$ & $193,230(8,1)$ \\
\hline 9 & & $161,210(7,0)$ & $161,210(7,0)$ \\
\hline 10 & \multirow{3}{*}{30} & $188,493.33(8,0)$ & $188,493.33(8,0)$ \\
\hline 11 & & $230,693.33(10,0)$ & $217,690(9,1)$ \\
\hline 12 & & $261,313.33(11,0)$ & $248,916.67(10,1)$ \\
\hline \multicolumn{2}{|c|}{$\begin{array}{l}\text { Average cost savings }(\%) \text { over } \\
\text { independent operations } \\
{[\min . \%, \max \%]}\end{array}$} & - & $1.24 \%[0 \%, 5.64 \%]$ \\
\hline
\end{tabular}

Table 1. Computational results for the local instances 1-12

\begin{tabular}{|c|c|c|c|c|}
\hline \multirow{2}{*}{ Instance } & \multirow{2}{*}{$\begin{array}{c}\text { No. of } \\
\text { customers }\end{array}$} & \multirow{2}{*}{$\begin{array}{c}\text { Depot } \\
\text { location }\end{array}$} & \multicolumn{2}{|c|}{$\begin{array}{c}\text { Monthly total cost in } \mathrm{HK} \$ \\
\text { (units required of resource } 2 \text {, resource } 1 \\
\text { respectively) }\end{array}$} \\
\hline & & & $\begin{array}{l}\text { Independent } \\
\text { operations } \\
(\text { Model } P)\end{array}$ & $\begin{array}{l}\text { Transfer, return } \\
\text { transport } \\
(\text { Model } \Gamma)\end{array}$ \\
\hline 13 & \multirow[t]{12}{*}{50} & \multirow{5}{*}{$\begin{array}{c}\text { Edge } \\
(100,0)\end{array}$} & $575,803.33(22,0)$ & $571,876.67(21,2)$ \\
\hline 14 & & & $507,416.67(19,0)$ & $507,416.67(19,0)$ \\
\hline 15 & & & $549,826.67(21,1)$ & $549,593.33(21,1)$ \\
\hline 16 & & & $667,530(26,0)$ & $663,743.33(25,2)$ \\
\hline 17 & & & $574,380(22,0)$ & $570,010(21,2)$ \\
\hline 18 & & \multirow{5}{*}{$\begin{array}{l}\text { Half- } \\
\text { way } \\
(50,0)\end{array}$} & $563,326.67(23,0)$ & $550,416.67(22,1)$ \\
\hline 19 & & & $522,783.33(21,0)$ & $522,783.33(21,0)$ \\
\hline 20 & & & $461,753.33(19,0)$ & $461,753.33(19,0)$ \\
\hline 21 & & & $528,016.67(22,0)$ & $515,083.33(21,1)$ \\
\hline 22 & & & $511,746.67(21,0)$ & $511,746.67(21,0)$ \\
\hline 23 & & \multirow{2}{*}{$\begin{array}{c}\text { Centre } \\
(0,0)\end{array}$} & $507,383.33(21,0)$ & $507,383.33(21,0)$ \\
\hline 24 & & & $511,630(21,0)$ & $511,630(21,0)$ \\
\hline
\end{tabular}




\begin{tabular}{|c|c|c|c|c|}
\hline 25 & & & $547,296.67(23,0)$ & $534,876.67(22,1)$ \\
\hline 26 & & & $529,136.67(22,0)$ & $519,890(21,1)$ \\
\hline 27 & & & $510,656.67(22,0)$ & $510,656.67(22,0)$ \\
\hline $\begin{array}{r}\mathrm{Av} \\
\text { indepen }\end{array}$ & $\begin{array}{l}\text { aving } \\
\text { lons }\end{array}$ & $\begin{array}{l}\text { ver } \\
\max . \%]\end{array}$ & - & $0.72 \%[0 \%, 2.45 \%]$ \\
\hline 28 & \multirow{15}{*}{100} & \multirow{5}{*}{$\begin{array}{l}\text { Edge } \\
(100,0)\end{array}$} & $997,333.33(38,0)$ & $962,616.67(35,3)$ \\
\hline 29 & & & $947,153.33(36,1)$ & $929,563.33(33,6)$ \\
\hline 30 & & & $975,066.67(37,2)$ & $927,443.33(30,14)$ \\
\hline 31 & & & $982,213.33(38,0)$ & $982,213.33(38,0)$ \\
\hline 32 & & & $929,420(36,1)$ & $902,940(33,5)$ \\
\hline 33 & & \multirow{5}{*}{$\begin{array}{l}\text { Half- } \\
\text { way } \\
(50,0)\end{array}$} & $833,150(33,3)$ & $833,150(33,3)$ \\
\hline 34 & & & $869,890(35,0)$ & $869,890(35,0)$ \\
\hline 35 & & & $971,370(39,1)$ & $968,120(38,3)$ \\
\hline 36 & & & $859,460(35,0)$ & $835,080(32,4)$ \\
\hline 37 & & & $728,590(29,1)$ & $722,183.33(27,5)$ \\
\hline 38 & & \multirow{5}{*}{$\begin{array}{l}\text { Centre } \\
(0,0)\end{array}$} & $762,926.67(31,1)$ & $761,310(30,3)$ \\
\hline 39 & & & $813,993.33(33,1)$ & $813,053.33(32,3)$ \\
\hline 40 & & & $761,853.33(31,0)$ & $761,853.33(31,0)$ \\
\hline 41 & & & $887,473.33(37,0)$ & $862,913.33(35,2)$ \\
\hline 42 & & & $887,590(37,0)$ & $864,943.33(35,2)$ \\
\hline \multicolumn{3}{|c|}{$\begin{array}{c}\text { Average cost savings (\%) over } \\
\text { independent operations [min.\%, max.\%] }\end{array}$} & - & $1.52 \%[0 \%, 4.88 \%]$ \\
\hline 43 & \multirow{15}{*}{150} & \multirow{5}{*}{$\begin{array}{l}\text { Edge } \\
(100,0)\end{array}$} & $1,200,736.67(46,0)$ & $1,172,693.33(43,4)$ \\
\hline 44 & & & $1,148,216.67(43,2)$ & $1,123,656.67(41,4)$ \\
\hline 45 & & & $1,087,723.33(41,2)$ & $1,071,773.33(39,5)$ \\
\hline 46 & & & $1,232,090(45,4)$ & $1,209,590(44,4)$ \\
\hline 47 & & & $1,114,983.33(42,1)$ & $1,111,570(41,3)$ \\
\hline 48 & & \multirow{5}{*}{$\begin{array}{l}\text { Half- } \\
\text { way } \\
(50,0)\end{array}$} & $1,152,856.67(46,1)$ & $1,135,343.33(44,4)$ \\
\hline 49 & & & $1,034,913.33(40,3)$ & $1,034,073.33(40,3)$ \\
\hline 50 & & & $1,045,536.67(41,2)$ & $1,034,906.67(39,6)$ \\
\hline 51 & & & $1,052,146.67(42,0)$ & $1,043,203.33(41,2)$ \\
\hline 52 & & & $1,291,133.33(50,2)$ & $1,252,816.67(46,6)$ \\
\hline 53 & & \multirow{5}{*}{$\begin{array}{l}\text { Centre } \\
(0,0)\end{array}$} & $1,128,910(45,2)$ & $1,128,186.67(45,2)$ \\
\hline 54 & & & $1,076,216.67(44,0)$ & $1,071,123.33(43,2)$ \\
\hline 55 & & & $1,089,400(44,1)$ & $1,088,996.67(43,3)$ \\
\hline 56 & & & $1,152,490(47,1)$ & $1,140,373.33(46,2)$ \\
\hline 57 & & & $1,063,540(43,1)$ & $1,056,533.33(42,3)$ \\
\hline \multicolumn{3}{|c|}{$\begin{array}{l}\text { Average cost savings (\%) over } \\
\text { independent operations [min. } \% \text {, max. } \%]\end{array}$} & - & $\begin{array}{c}1.12 \% \\
{[0.04 \%, 2.97 \%]}\end{array}$ \\
\hline
\end{tabular}

Table 2. Computational results for the simulated instances 13-57 
The observations from the computational experiments are summarized as follows:

- Both models could be solved to optimality for all 57 instances within reasonable time. The maximum running time is within 1,200 CPU seconds for instances of up to 150 customers.

- In all instances, the cooperative model (Model $\Gamma$ ) allowing documents transfer and return transporation performs at least as good as the independent model (Model $P$ ). The percentage of cost savings could be as much as $5 \%$, with an average between $1-2 \%$. (As the network $\Pi^{\top}$ is expanded from the network $\Pi$ of the independent model, the solution quality cannot be worse. Surprisingly, the computational time taken for both models are quick for instances of up to 150 customers.)

- $\quad$ The travel speed of resource 1 (couriers on foot) is relatively slower than resource 2 (vans). Return transportation by resource 2 is found more frequent when cooperative operations do occur. The number of resource 1 units used is small and they only serve a few customers (resulting in low resource utilization), as compared with resource 2 units.

- Some system characteristics will favor cooperative operations. When problem size increases or when the depot location is away from the customer centroid (say half-way, or at the edge of the service region), the optimal solution contains more cooperative operations, in particular, return transportation of resource 1 by resource 2 .

There are naturally limitations of this work that need to be pointed out. Real data could contain clusters of nearby customer locations that would make it difficult to enumerate all customer groups. Some clustering of service areas could be carried out before applying any model. Scheduling and routing problems are often affected by factors that are not easily formulated by optimization models (e.g., personal preferences, fairness of assignment). Other complex factors in routing include the use of public transport, traffic congestion, turn restrictions on streets (Irnich, 2008) would require heuristics and communication technologies for real-time monitoring and control.

\section{Conclusion}

This work is a continuation of an earlier work on routing courier services (Lin, 2008). It contributes to studies on multi-resource scheduling in pickup and delivery operations by modelling certain cooperative operations. The static-deterministic problem could be formulated by a (mixed) integer programming model and for the 57 instances generated from real data and simulated data (consisting of up to 150 customers), the computational time is within 1,200 CPU seconds. With the slower resource as courier and the faster resource as van, return transportation of the slower unit(s) by a faster unit is found to generate cost savings for certain data sets (e.g., Figure 3). Monthly cost savings were achieved at an average of $1-2 \%$ (maximum of $5 \%$ ) over the independent operations. For the courier industry which has experienced considerable growth in South-east Asia, a few percent of monthly total cost could represent large dollar savings in the long-run. As fuel cost rises, saving in travelling cost is expected to further increase. The optimization component could be further incorporated into intelligent transportation systems with route guidance system to improve the operational efficiency (Jung et al., 2006). Further interesting research directions include modelling the outbound transportation of the lighter resource by the heavier resource and developing heuristics for solving large problems efficiently, when the IP model requires large computational resource.

This work contributes to modelling cooperation and developing methods to solve hard delivery problems in real situations. In actual practice of courier companies, some cooperative strategies are in action but without sound theory to justify performance or to explore further improvement. 


\begin{tabular}{|c|c|c|c|c|}
\hline \multirow[t]{2}{*}{ Instance } & \multirow{2}{*}{\multicolumn{2}{|c|}{ No. of customers }} & \multicolumn{2}{|l|}{ CPU seconds } \\
\hline & & & $\begin{array}{l}\text { Independent operations } \\
(\text { Model } P)\end{array}$ & $\begin{array}{l}\text { Transfer, return transport } \\
(\text { Model } \Gamma)\end{array}$ \\
\hline 1 & \multirow{4}{*}{\multicolumn{2}{|c|}{27}} & 4.62 & 4.6 \\
\hline 2 & & & 5.28 & 4.57 \\
\hline 3 & & & 6.1 & 4.46 \\
\hline 4 & & & 4.16 & 6.81 \\
\hline 5 & \multirow{5}{*}{\multicolumn{2}{|c|}{29}} & 25.2 & 11.85 \\
\hline 6 & & & 13.33 & 7.29 \\
\hline 7 & & & 6.41 & 6.77 \\
\hline 8 & & & 10.79 & 8.89 \\
\hline 9 & & & 10.41 & 173.08 \\
\hline 10 & \multirow{3}{*}{\multicolumn{2}{|c|}{30}} & 9.64 & 12.94 \\
\hline 11 & & & 7.38 & 13.26 \\
\hline 12 & & & 8.45 & 90.59 \\
\hline \multirow[t]{2}{*}{ Instance } & \multirow{2}{*}{$\begin{array}{l}\text { No. of } \\
\text { customers }\end{array}$} & \multirow{2}{*}{$\begin{array}{l}\text { Depot } \\
\text { location }\end{array}$} & \multicolumn{2}{|l|}{ CPU seconds } \\
\hline & & & $\begin{array}{l}\text { Independent operations } \\
(\text { Model } P)\end{array}$ & $\begin{array}{l}\text { Transfer, return transport } \\
(\text { Model } \Gamma)\end{array}$ \\
\hline 13 & \multirow[t]{15}{*}{50} & \multirow{5}{*}{$\begin{array}{l}\text { Edge } \\
(100,0)\end{array}$} & 11.33 & 10.97 \\
\hline 14 & & & 12.41 & 12.77 \\
\hline 15 & & & 12.59 & 12.07 \\
\hline 16 & & & 10.83 & 12.65 \\
\hline 17 & & & 12.18 & 11.53 \\
\hline 18 & & \multirow{5}{*}{$\begin{array}{l}\text { Half-way } \\
(50,0)\end{array}$} & 14.46 & 10.71 \\
\hline 19 & & & 11.31 & 11.67 \\
\hline 20 & & & 12.1 & 11.85 \\
\hline 21 & & & 10.73 & 11.88 \\
\hline 22 & & & 12.56 & 12.11 \\
\hline 23 & & \multirow{5}{*}{$\begin{array}{l}\text { Centre } \\
(0,0)\end{array}$} & 14.28 & 12.73 \\
\hline 24 & & & 15.34 & 12.36 \\
\hline 25 & & & 17.6 & 11.64 \\
\hline 26 & & & 18.35 & 12.22 \\
\hline 27 & & & 11.75 & 11.52 \\
\hline
\end{tabular}




\begin{tabular}{|c|c|c|c|c|}
\hline 28 & \multirow[t]{15}{*}{100} & \multirow{5}{*}{$\begin{array}{l}\text { Edge } \\
(100,0)\end{array}$} & 39.11 & 38.82 \\
\hline 29 & & & 45.67 & 40.75 \\
\hline 30 & & & 39.17 & 39.24 \\
\hline 31 & & & 38.03 & 43.53 \\
\hline 32 & & & 38.79 & 46.71 \\
\hline 33 & & \multirow{5}{*}{\begin{tabular}{|l} 
Half-way \\
$(50,0)$
\end{tabular}} & 40 & 42.56 \\
\hline 34 & & & 42.39 & 85.17 \\
\hline 35 & & & 46.54 & 99.98 \\
\hline 36 & & & 42.35 & 52.55 \\
\hline 37 & & & 41.7 & 46.67 \\
\hline 38 & & \multirow[t]{5}{*}{ Centre $(0,0)$} & 41.53 & 46.03 \\
\hline 39 & & & 41.82 & 51.15 \\
\hline 40 & & & 47.01 & 45.72 \\
\hline 41 & & & 39.53 & 43.12 \\
\hline 42 & & & 43.22 & 38.8 \\
\hline 43 & \multirow[t]{15}{*}{150} & \multirow{5}{*}{$\begin{array}{l}\text { Edge } \\
(100,0)\end{array}$} & 102.3 & 149.22 \\
\hline 44 & & & 135.8 & $1,079.25$ \\
\hline 45 & & & 110.93 & 537.2 \\
\hline 46 & & & 99.72 & 110.08 \\
\hline 47 & & & 121.64 & 303.17 \\
\hline 48 & & \multirow{5}{*}{$\begin{array}{l}\text { Half-way } \\
(50,0)\end{array}$} & 138.21 & 1,019.17 \\
\hline 49 & & & 129.43 & 714.23 \\
\hline 50 & & & 566.5 & 629.97 \\
\hline 51 & & & 142.65 & 440.06 \\
\hline 52 & & & 119.13 & 196.46 \\
\hline 53 & & \multirow{5}{*}{$\begin{array}{l}\text { Centre } \\
(0,0)\end{array}$} & 88.36 & 179.43 \\
\hline 54 & & & 139.76 & 717.35 \\
\hline 55 & & & 105.91 & 299.05 \\
\hline 56 & & & 91.06 & 119.78 \\
\hline 57 & & & 119.72 & 478.24 \\
\hline
\end{tabular}

Table 3. Computational time of instances 1-57 (local: 1-12; simulated: 13-57) 


\section{References}

Brpnmo, G.; Christiansen, M. \& Nygreen, B. (2007). Ship routing and scheduling with flexible cargo sizes. Journal of the Operational Research Society, Vol. 58, No. 9, September 2007, 1167-1177, ISSN: 01605682

Chao, I.-M. (2002). A tabu search method for the truck and trailer routing problem. Computers \& Operations Research, Vol. 29, No. 1, January 2002, 33-51, ISSN: 03050548

Irnich, S. (2008). Solution of real-world postman problems. European Journal of Operational Research, Vol. 190, No. 1, October 2008, 52-67, ISSN: 0377-2217

Jung, H.; Lee, K. \& Chun, W. (2006). Integration of GIS, GPS, and optimization technologies for the effective control of parcel delivery service, Computers $\mathcal{E}$ Industrial Engineering, Vol. 52, No. 4, September 2006, 154-162, ISSN: 0360-8352

Kamoun, M. \& Hall, R.W. (1996). Design of express mail services for metropolitan regions. Journal of Business Logistics, Vol. 17, No. 2, 1996, 265-302, ISSN: 0735-3766

Langevin, A. \& Soumis, F. (1989). Design of multiple-vehicle delivery tours satisfying time constraints. Transportation Research Part B, Vol. 23, No. 2, April 1989, 123-138, ISSN: 0191-2615

Lin, C.K.Y. (2008). A cooperative strategy for a vehicle routing problem with pickup and delivery time windows. Computers $\mathcal{E}$ Industrial Engineering, in press, ISSN: 03608352

Lu, Q. \& Dessouky, M.M. (2006). A new insertion-based construction heuristic for solving pickup and delivery problem with time windows. European Journal of Operational Research, Vol. 175, No. 2, December 2006, 672-687, ISSN: 0377-2217

Mitrović-Minić, S.; Krishnamurti, S., R. \& Laporte, G. (2004). Double-horizon based heuristics for the dynamic pickup and delivery problem with time windows. Transportation Research Part B, Vol. 38, No. 8, September 2004, 669-685, ISS: 01912615

Mitrović-Minić, S. \& Laporte, G. (2004). Waiting strategies for the dynamic pickup and delivery problem with time windows. Transportation Research Part B, Vol. 38, No. 7, September 2004, 635-655, ISSN: 0191-2615

Mitrovic-Minic, S. \& Laporte, G. (2006). The pickup and delivery problem with time windows and transshipment. INFOR, Vol. 44, No. 3, August 2006, 217-227, ISSN: 0315-5986

Ropke, S. \& Pisinger, D. (2006). A unified heuristic for a large class of vehicle routing problems with backhauls. European Journal of Operational Research, Vol. 171, No. 3, June 2006, 750-775, ISSN: 0377-2217

Savelsbergh, M.W.P. \& Sol, M. (1995). The general pickup and delivery problem. Transportation Science, Vol. 29, No. 1, February 1995, 17-29, ISSN: 0041-1655

Scheuerer, S. (2006). A tabu search heuristic for the truck and trailer routing problem. Computers \& Operations Research, Vol. 33, No. 4, April 2006, 894-909, ISSN: 0305-0548

Semet, F. (1995). A two-phase algorithm for the partial accessibility constrained vehicle routing problem. Annals of Operations Research, Vol. 61, No. 1-4, December 1995, 4565, ISSN: 0254-5330 
Shang, J.S. \& Cuff, C.K. (1996). Multicriteria pickup and delivery problem with transfer opportunity. Computers \& Industrial Engineering, Vol. 30, No. 4, September 1996, 631-645, ISSN: 0360-8352

Transport Department, Hong Kong. (2001). Car journey time survey for monitoring traffic congestion, Hong Kong.

Yu, V.F.; Lin, S.-W. \& Chou, S.-Y. (2008). Solving the truck and trailer routing problem based on a simulated annealing heuristic. Computers $\mathcal{E}$ Operations Research, in press, ISSN: 0305-0548 


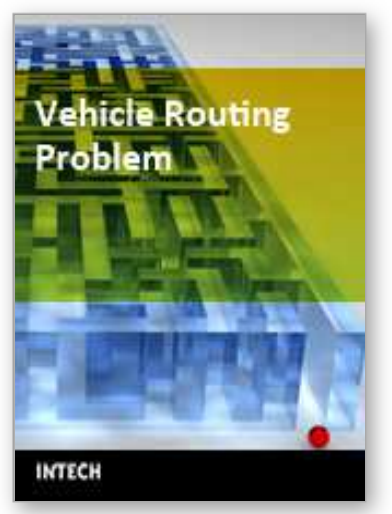

\author{
Vehicle Routing Problem \\ Edited by Tonci Caric and Hrvoje Gold
}

ISBN 978-953-7619-09-1

Hard cover, 142 pages

Publisher InTech

Published online 01, September, 2008

Published in print edition September, 2008

The Vehicle Routing Problem (VRP) dates back to the end of the fifties of the last century when Dantzig and Ramser set the mathematical programming formulation and algorithmic approach to solve the problem of delivering gasoline to service stations. Since then the interest in VRP evolved from a small group of mathematicians to a broad range of researchers and practitioners from different disciplines who are involved in this field today. Nine chapters of this book present recent improvements, innovative ideas and concepts regarding the vehicle routing problem. It will be of interest to students, researchers and practitioners with knowledge of the main methods for the solution of the combinatorial optimization problems.

\title{
How to reference
}

In order to correctly reference this scholarly work, feel free to copy and paste the following:

C.K.Y. Lin (2008). Resources Requirement and Routing in Courier Service, Vehicle Routing Problem, Tonci Caric and Hrvoje Gold (Ed.), ISBN: 978-953-7619-09-1, InTech, Available from:

http://www.intechopen.com/books/vehicle_routing_problem/resources_requirement_and_routing_in_courier_s ervice

\section{INTECH}

open science | open minds

\section{InTech Europe}

University Campus STeP Ri Slavka Krautzeka 83/A 51000 Rijeka, Croatia

Phone: +385 (51) 770447

Fax: +385 (51) 686166 www.intechopen.com

\section{InTech China}

Unit 405, Office Block, Hotel Equatorial Shanghai No.65, Yan An Road (West), Shanghai, 200040, China 中国上海市延安西路65号上海国际贵都大饭店办公楼405单元 Phone: +86-21-62489820

Fax: +86-21-62489821 
(C) 2008 The Author(s). Licensee IntechOpen. This chapter is distributed under the terms of the Creative Commons Attribution-NonCommercialShareAlike-3.0 License, which permits use, distribution and reproduction for non-commercial purposes, provided the original is properly cited and derivative works building on this content are distributed under the same license. 